\title{
Towards improved forecasting for offshore wind turbine O\&M transfers
}

\author{
P.R. Mills, B. Stephen \& D. McMillan \\ Electronic \& Electrical Engineering University of Strathclyde, Glasgow, UK \\ I. Lazakis \\ Naval Architecture, Ocean and Marine Engineering University of Strathclyde, Glasgow, UK
}

\begin{abstract}
Failure to adequately account for marine conditions can incur uncertainty in operation and maintenance costs for offshore renewable installations. Winter months with high potential for electricity generation coincide with the conditions where access for maintenance is most challenging. Advancing towards a demonstration of a strategic maintenance approach will assist in both reducing direct costs and associated initial project finance, while informing this with a better understanding of the impact of marine conditions could improve crew transfer vessel logistics and planning. This paper presents historical weather data close to East Anglia One Wind Farm for use in the development of vessel access models. The research provides a forecasting methodology for predicting wave directions at a site close to the wind farm. Improved ability to predict wave direction could improve existing and future modelling of the impact of marine conditions on the speed and fuel usage of vessels. Potential also exists for directional information to be utilised in scheduling transfer operations.
\end{abstract}

\section{INTRODUCTION}

Offshore wind generated over $5 \%$ of the UK's electricity needs in 2015 and is on a trajectory to reach an installed capacity of $10 \mathrm{GW}$ by 2020 (Crown Estate, 2016). Optimising availability is critical to national security of supply. Offshore wind turbine availabilities are of the order of $73-83 \%$ compared to onshore equivalents at 97\% (Dinwoodie et al. 2012) incurring lower generation revenues from plant with a higher capital outlay. Operation and maintenance $(\mathrm{O} \& \mathrm{M})$ costs are significant accounting for around $30 \%$ of overall project lifetime costs (Dinwoodie et al. 2013) and of the order of $£ 25-40$ million for a typical 500MW wind farm (BVG Associates, 2010), so pursuing a strategic maintenance approach will both reduce direct costs and, through increasing investor confidence, those of raising initial project finance.

Reducing the costs of initial investment is critical: if initial finance is unavailable at an economical rate, then a project cannot proceed since higher initial capital costs will increase interest rates, impacting on its economic viability. Maximising plant uptime by reducing the uncertainties in maintenance scheduling can be addressed through anticipating and understanding weather conditions better.

Monitoring waves is critical to safe access for offshore wind turbines from vessels, so identifying future time periods when access vessels cannot operate will reduce costs incurred by aborted missions.

Section 2 reviews existing literature on metrological modelling, Section 3 introduces the data study site off the East Anglian coast. Section 4 gives a preliminary analysis of the data. Section 5 outlines the methodology for a conditional inter-site wave direction forecast, Section 6 present results with conclusions in Section 7.

\section{METROLOGICAL FACTORS}

The papers reviewed give details on the types of forecasts used for short to medium term forecasts. For forecasts shorter than six hours in advance simpler simulations are needed to deliver results quickly. The literature illustrates the relationships between wind and wave variables and weather windows when conditions are below the limits for an adequate time period.

Weather prediction is a paramount and challenging factor in determining whether access for maintenance is possible. For example if the maximum wave height for operating a jack-up vessel is $2 \mathrm{~m}$ (HGO InfraSea Solutions, 2014), any higher maximum wave height breaches safety limits leading to the operation being terminated. Other conditions such as visibility may vary over the transfer route and the decision will be less binary. Most weather 
variables are location specific; this is an issue as measurement stations are at particular sites that may not be representative of the specific locations.

Metrological data is available, but the time resolution is too coarse. Wind and wave observations are not available at all sites, reanalysis and hindcasts allow the prediction of marine conditions at sites where data is not recorded. Calibration for directions allows more accurate hindcasts of wind and wave conditions (Espejo et al. 2011). The correlation between wind speed and lagged significant wave height shows a maximum correlation when the lag is 4 hours for the particular site of FINO 1 (Dowell et al. 2013). FINO 1 is a $100 \mathrm{~m}$ mast in the North Sea, $45 \mathrm{~km}$ North of Borkhum in Germany with a water depth of around $30 \mathrm{~m}$.

Predicting the probability of delays to the maintenance of offshore wind turbines caused by marine conditions can inform access logistics. Possible scenarios are excessive wave heights or narrow weather windows incurred by calm periods not long enough to perform maintenance (Feuchtwang and Infield, 2013). A slight improvement in transportation means access capabilities can result in significant improvement in access and reductions in maintenance delays (Dowell et al. 2013). Table 1 provides example of transportation access capabilities.

Table 1. Generic Maximum operating wave heights and wind speeds for a selection of transportation means (Dalgic et al. 2013, 2015a, b).

\begin{tabular}{lll}
$\begin{array}{l}\text { Transportation } \\
\text { means }\end{array}$ & $\begin{array}{c}\text { Max wave height } \\
\mathrm{m}\end{array}$ & $\begin{array}{c}\text { Max wind speed } \\
\mathrm{m} / \mathrm{s}\end{array}$ \\
\hline Helicopter & 4 & 18 \\
SWATH* & $1.5-2$ & \\
CTV & 1.5 & 25 \\
OAV & 2 & 25 \\
Jack-up & 2.8 & 36.1 \\
Leg-stabilised & 0.5 & \\
\hline
\end{tabular}

*Small Waterplane Area Twin Hull

Helicopters while much more expensive can be used as a last resort for crew and component transfer; however even they are limited by wave height due to the risk of helicopter ditching. A helicopter study compares winds, waves and cloud cover on helicopter availability including using persistence and autoregressive moving average forecasts (DominguezNavarro et al. 2014). The wind direction can impact on helicopter hover (Civil Aviation Authority of New Zealand. 2012). Safe crew and component transfers from helicopters to turbine require understanding and planning for wind conditions including wind direction. However, models such as autoregressive moving average are unsuitable for directional data.

Hill outline such a methodology for forecasting, up to 6 hours in advance. The lack of available offshore observations resulted in the use of metrologically modelled, offshore weather data (Hill et al.
2014). Due to the limited availability of offshore wind speeds an understanding of the differences between onshore and offshore wind speeds can inform the use of onshore data. Like onshore, offshore wind speeds are affected by surface roughness. However due to the variability of the sea state the roughness changes. Charnock's relation relates roughness length with wind stress. Charnock's relation can be extended to include other variables such as wave age, fetch, water depth, wave height and Reynolds number, however; they can be difficult to measure. The availability of data from offshore meteorological masts is relatively new. Offshore met masts include, Rodsand in the Baltic Sea, and Hons Rev and FINO in the North Sea.

For the $62 \mathrm{~m}$ tall Rodsand mast, even with a fetch of $30 \mathrm{~m}$, wind profiles are a superposition of both land and sea profiles, illustrating the importance of the surrounding land in the modelling of maritime winds. Pena et.al 2008 uses dimensionless wind speeds, heights and stability to extract the dependence of wind speeds on roughness length. The article illustrates a model for predicting maritime wind profiles. Charnock's relation, an empirical expression for aerodynamic roughness length, has a strong effect on scaling height (Peña and Gryning, 2008). This research illustrates the impact of sea state on roughness length and hence wind speeds.

Andreas and Wang analyse hourly wave height and wind speed data from 12 buoys off the North East coast of the USA over an 18 year period. The study requiring only water depth and wind speed finds a strong relation between wind speeds and wave heights with a stronger correlation at lower wave heights and wind speeds (Andreas and Wang, 2007). Espejo identifies a relationship between directions of wind speeds and wave heights (Espejo et al. 2011).

Literature cites four key operations and maintenance models, some of the models use historical weather data while others use synthetically generated weather time series. Use of the same historical data for all models produced similar results, suggesting that the weather data time series used causes the biggest difference between the models (Dinwoodie et al. 2015). The Energy Research Centre of the Netherlands $(\mathrm{ECN})$ have developed a cost and operation and maintenance optimisation tool. This model takes account of failure behaviour, repair strategies, access, lifting systems, labour costs and weather conditions. Weather conditions represented in the model include wind, waves, lightning and visibility (Rademakers et al. 2014). Garrad Hassan produce the $\mathrm{O} 2 \mathrm{M}$ tool which provides costs and lost production (Hofmann, 2011).

Direction and speed can be multi-modal and there may be coupling between speed and direction. The speed or directional regimes associated with such modes indicate if it is multi-modal. The analysis 
study splits prevailing site conditions into a number of regimes. The study concludes that the use of mixture models has the advantage over the use of Weibull distributions in that multimodal studies can be performed (Stephen et al. 2013).

Many studies assume full use of weather windows. However, this would assume perfect forecasting of weather windows which is not viable (Browell 2016, Shafiee 2015). For this reason, forecasts are required, there is existing research forecasting wind speeds and wave heights (Dinwoodie et al. 2012; Dowell et al. 2013), however, research predicting wave directions is more limited, and hence a wave direction prediction model will be presented. Such a model could also be used for wind direction forecasting.

This section has provided research into the relationship between wind and waves which along with forecasting and measurement of these variables can inform when and for how long conditions are suitable for operation and maintenance vessel operations. The next section introduces the weather stations analysed in this study.

\section{CASE STUDY}

East Anglia One, a third development round wind farm has 102 turbines rated at $7 \mathrm{MW}$ with a water depth of 30- $42 \mathrm{~m}$. Figure 1 shows the $297 \mathrm{~km}^{2}$ area of the site which has a distance of $53.8 \mathrm{~km}$ from the shore at the centre (4C Offshore, 2015). A case study of East Anglia One Wind Farm allows modelling close to an actual site. The case study gives a realworld context and provides the potential to obtain data from developers to validate findings at a future date.

This study addresses the development of a model that relates wave directions for the selected offshore sites. The closest CEFAS wave data sites are Southwold approach and West Gabbard as shown in Figure 1 (Centre for Environment Fisheries and Aquaculture Science. 2016). The nearshore wave data for Southwold Approach is approximately $7 \mathrm{~km}$ from shore. The further offshore wave heights of West Gabbard at $36 \mathrm{~km}$ is illustrated in Figure 1. The peak wave direction is the direction that the waves with the most energy are approaching from. Wind speed and direction data is also presented as it is intended that the forecasting model could be adapted for use with wind direction data. Of the MIDAS (Met Office Integrated Data Archive System) onshore wind speed data stations, Yarmouth is the closest to East Anglia One Wind Farm (UK Meteorological Office. 2015). Wind directions are also for the direction winds are approaching from. The following section develops a methodology for comparison between the sites in Figure 1 including key marine weather conditions safety limitations for vessels.

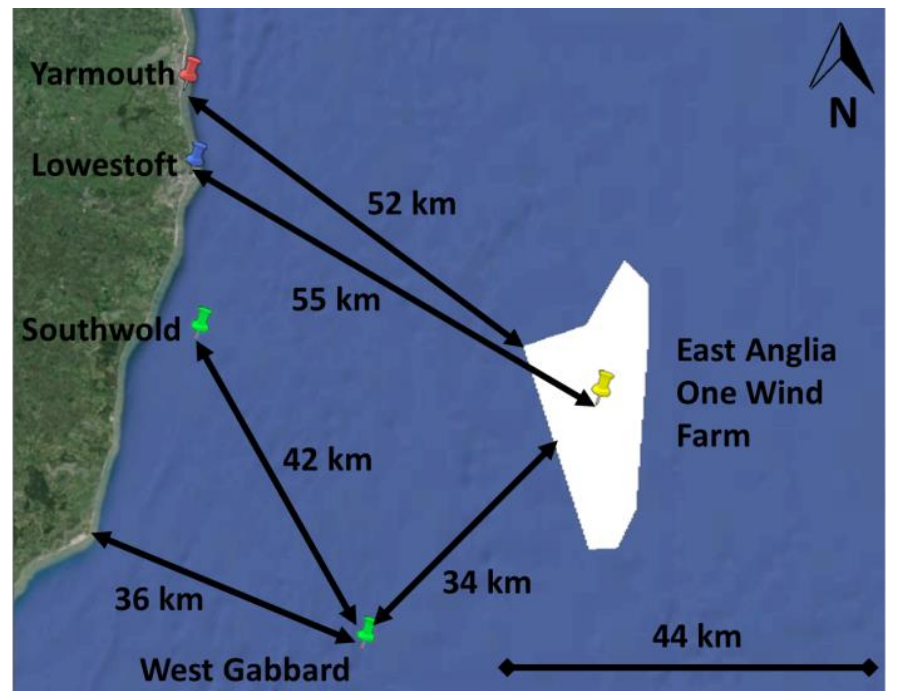

Figure 1. Map showing location of East Anglia One Wind Farm and measurement stations (Centre for Environment Fisheries and Aquaculture Science. 2016; UK Meteorological Office. 2015).

\section{PRELIMINARY ANALYSIS}

A third development round wind farm was selected to be representative of the challenging marine conditions faced by wind farms under development, specifically further offshore placement and higher wave heights. Critical access constraints were identified and are summarised in Table 1 for vessels most applicable to this study.

For each site two variables were studied: one for the magnitude of winds or waves and the other for the direction. For hourly mean wind speed the original observations were in knots and are converted to metres per second before analysis. Where wave height is referred to this is the significant wave height which is the highest one-third of waves. The data is at half hourly intervals. The dominant peak wave direction was chosen over the mean wave direction due to the greater data coverage for the dominate peak direction variable. Where in the text, wave direction is used this refers to the dominant peak wave direction. An initial pilot study compared one year of data for three weather stations. The results presented are for the longer time periods as presented in Table 2. A forecasting methodology for wave directions at Gabbard with those at Southwold is provided in section 5 with results in section 6 .

Table 2. Data coverage (Centre for Environment Fisheries and Aquaculture Science. 2016; UK Meteorological Office. 2015)

\begin{tabular}{llll}
\hline Data Coverage & Gabbard & Yarmouth* & Southwold \\
\hline Start & $28 / 08 / 2002$ & 2002 to 07 & $01 / 04 / 2010$ \\
End & $18 / 02 / 2016$ & 2010 to 12 & $18 / 02 / 2016$ \\
\hline
\end{tabular}

*no data in 2008 or 2009

An analysis of the data was conducted as follows: Wind and wave directional rose diagrams are used to 


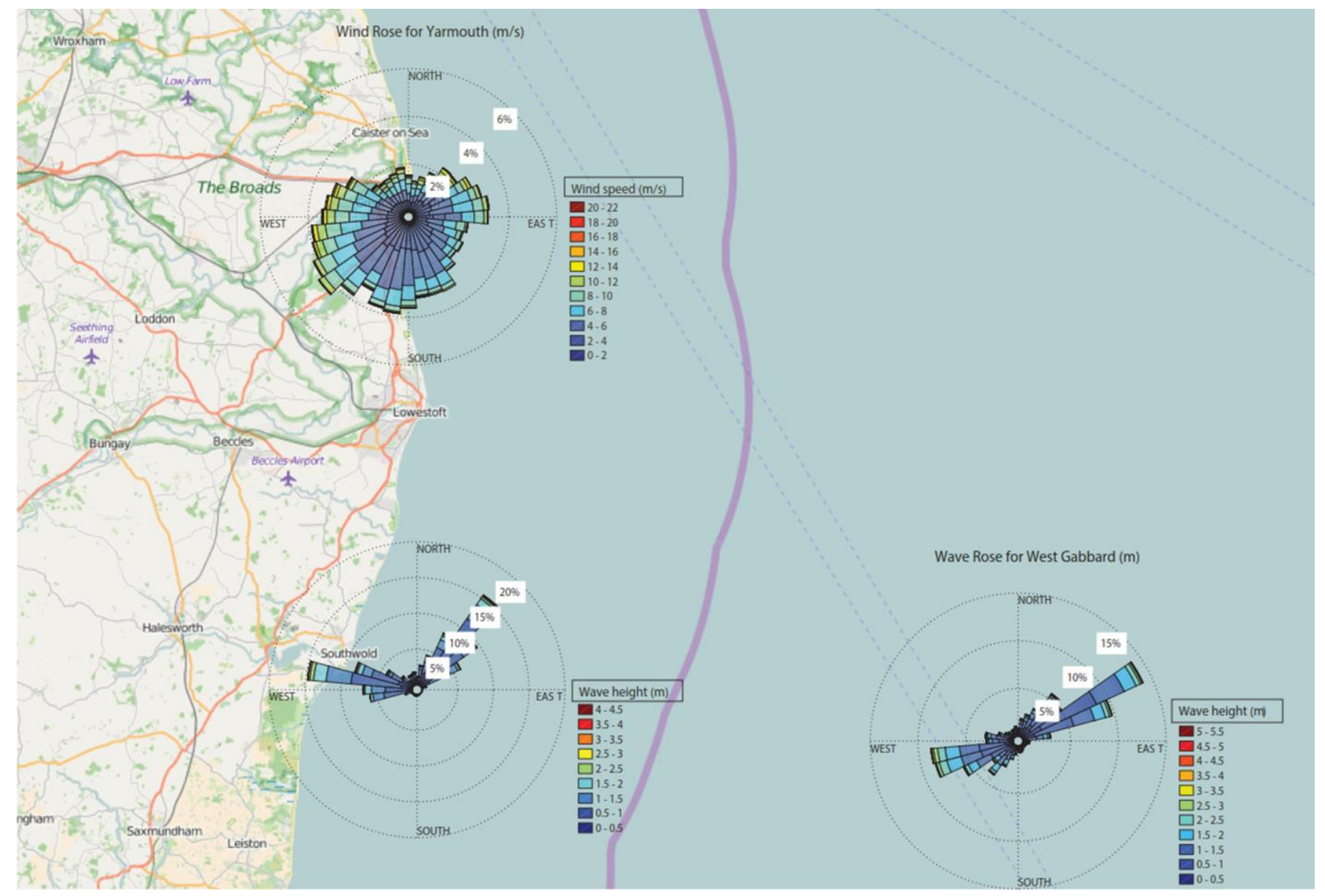

Figure 2. Rose diagrams for the measurement stations in the region of interest.

identify the most frequent directions. The directional wind and wave roses quantify both the magnitude and directional segments. Significant wave height (m) is binned in intervals of $0.5 \mathrm{~m}$. Wind speed $(\mathrm{m} / \mathrm{s})$ is binned in intervals of $2 \mathrm{~m} / \mathrm{s}$. A twodimensional histogram (Stephen et al. 2013), is used to examine the impact of binned wave height or wind speed against the binned directions. The vessel limitation thresholds see, Table 1, are applied to the results and conclusions drawn about how the results will impact on vessels. The next section outlines the results of the analysis of these weather stations.

The direction of waves is an important factor in vessel transfers due to the impact on vessel speed and stability. Figure 2 shows that there are two modes of wave heights by direction for West Gabbard, which results in an unreliable mean. The dominant mode is in the North East quadrant. The second mode is in the South West quadrant. Wind directions for Yarmouth are predominantly to the South West as shown in Figure 2. However, Figure 2 also shows that wind speeds above $12 \mathrm{~m} / \mathrm{s}$ are most common between West South West and North East. There is one mode predominantly in the South West quadrant. It can be seen that this mode extends into the North West and South East quadrants. A frequent occurrence of low wind speeds will skew the results as frequent low wind speed is of limited relevance to the case studied. Figure 2 shows two modes for
Southwold; the first is in the North East. The second mode is North, North West.

For Yarmouth the most common direction is 210 degrees. The mean direction of 226 degrees is sensible as wind directions South West of 219 degrees are more frequent than those between East and South. For Southwold, the mean direction is 107 degrees; a very uncommon wave direction. This is the mean of the two directional modes. For West Gabbard the mean direction is 116 degrees, this corresponds to a point half wave between the two modes showing the use of the mean is unreliable for multimodel data. Southwold has the lowest circular variance. The mean of hourly mean wave directions for Southwold and West Gabbard are close. However, the mean of hourly mean wind speeds for Yarmouth is in a different direction towards the South West.

Figures 3-5 show heatmaps for the locations studied. These are two-dimensional histograms of magnitudes and directions where the magnitudes of wind speeds and wave heights are binned on the horizontal axis. On the vertical axis are the directions which are also in binned intervals. The squares on the histogram are for values which are within the binned intervals for both magnitude and direction. The number of occurrences, in hours of each of these bin combinations, is shown on the scale at the right of the graphs.

Figure 3 shows two modes; one around 25 degrees the other around 200 degrees. The first mode 
which is closer to North is clearly the dominant mode with the number of occurrences of over 4,500 hours for the bin around $0.5 \mathrm{~m}$ wave height and 30 degrees. This mode has a high frequency of occurrence of over 4000 for these directions up to a wave height of over $1 \mathrm{~m}$. The mode extends to higher wave heights but above $2 \mathrm{~m}$ the frequency is minimal. The 2 nd mode has frequencies of occurrence of around 2,500 and extends over a larger range of directions than the first one. Above $2.5 \mathrm{~m}$ the number of occurrences for each direction is negligible, and no conclusions about dominant directions can be drawn from this analysis.

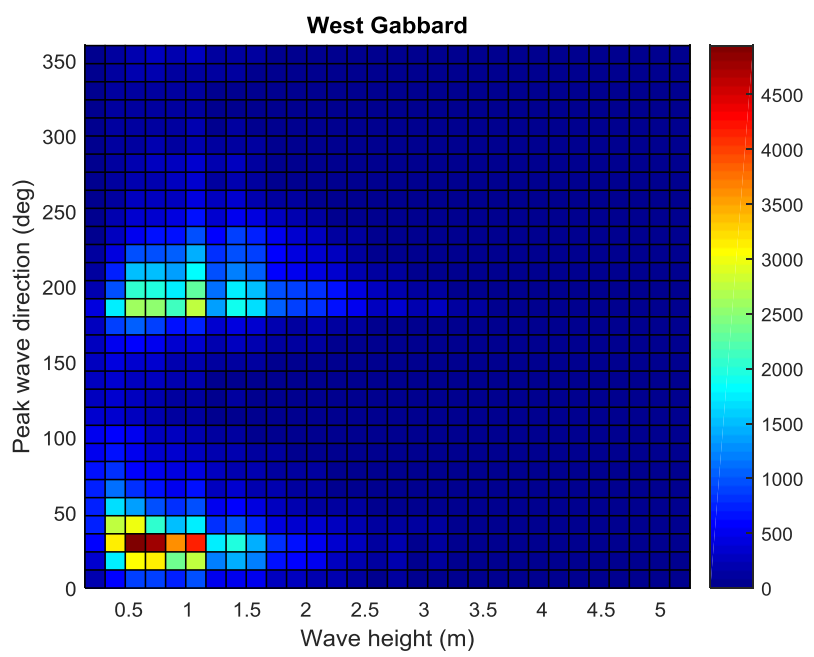

Figure 3. West Gabbard wave height histogram for 2002 to 2016.

Figure 4 shows a two-dimensional histogram of wind speeds and directions for Yarmouth. The peak of occurrence is at wind speeds of around $4 \mathrm{~m} / \mathrm{s}$ and directions of around 245 degrees. This bin square has frequencies of over 700 , with no other combination of binned winds speeds and directions having the number of occurrences of hours over 500. There are only two bin with squareds with frequencies of occurrence in hours over 400, this second relatively isolated bin is also for winds around $4 \mathrm{~m} / \mathrm{s}$ but with the direction of around 300 degrees which is approximately North West. This shows a complexity to the wind regime not visible on the wind rose diagrams.

At wind speed of around $9 \mathrm{~m} / \mathrm{s}$ the most frequent direction is approximately 180 degrees, this indicates Southerly winds are more frequent at higher wind speeds. The wind speeds histogram show a less clear pattern of winds than those for waves in Figure 3 and Figure 5 possibly due to more varied wind speeds and directions. Waves appear to be more likely to follow trends possibly due to local geographical features.

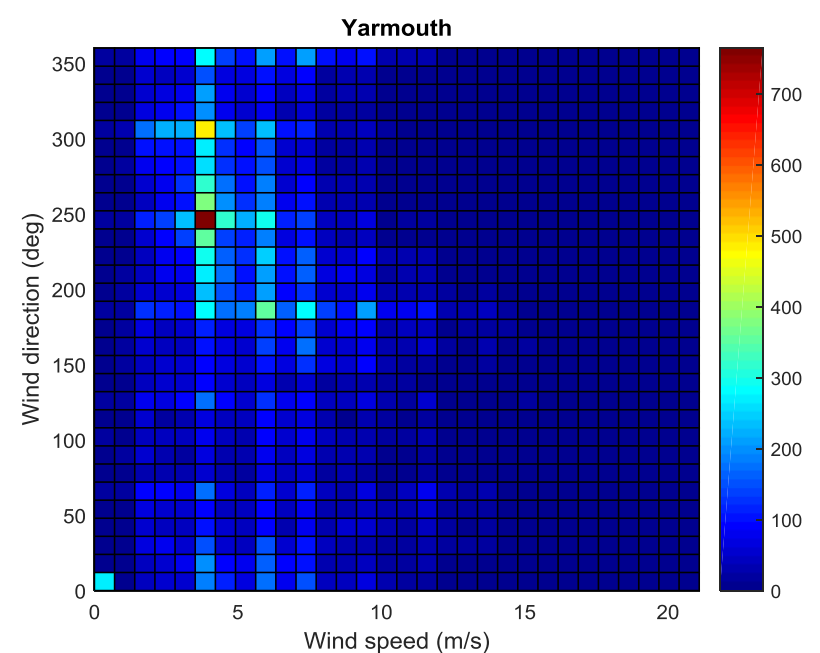

Figure 4. Yarmouth windspeed histogram for 2002 to 07 \& 2010 to 12 .

Figure 5 shows two modes for the Southwold wave data. Both modes have a maximum frequency of occurrence for wave heights between 0.2 and $1.2 \mathrm{~m}$. The first more dominate mode is for directional sectors around 40 degrees with a frequency of occurrence of over 3,000. The second less dominant mode is in directional sectors between 150 to 180 degrees with a frequency of occurrence, in hours, of up to 2,000 . Both modes extend up to wave heights of 2.1 $\mathrm{m}$ but above this the impact of direction is not visible due to the almost zero number of occurrences at these wave heights and directions.

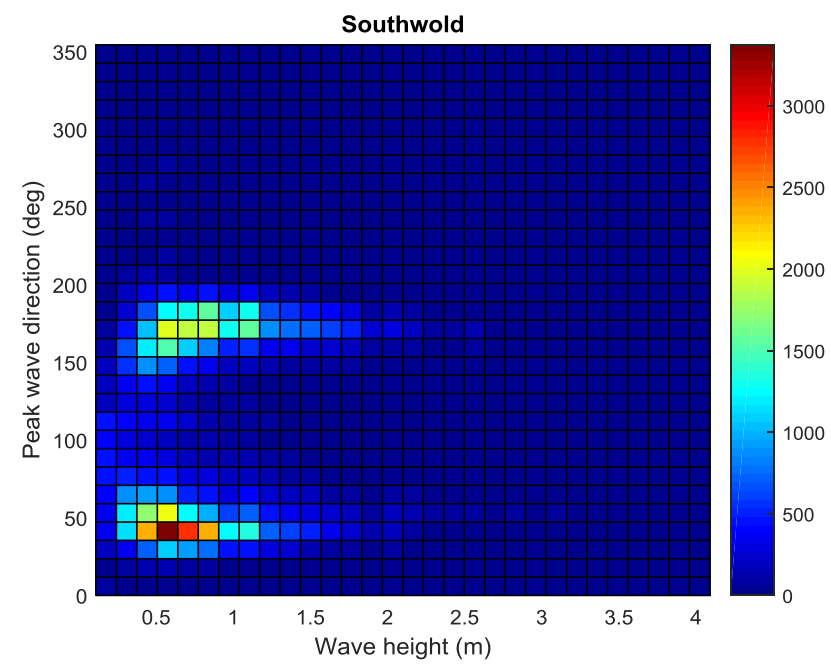

Figure 5. Southwold wave height histogram for 2010 to 2016.

\section{INTER-SITE MARINE CONDITIONS MODEL}

Failure to take account of sea and wind conditions on vessel transit time will tend to over-state availability and yield predictions for offshore wind therefore it is important that these are captured in the model. Studies to calculate the speed loss and achievable speed first calculate vessel added and total resistance, (Dalgic et al. 2015a). Resistance calculations require the wind and wave direction (Szelangiewicz and Żelazny, 2006). However, esti- 
mates of wind and wave direction will not be available at all points throughout the vessel transfer. This paper presents a model for estimating wave directions at one site based on wave directions at another. In this case the modelling site for predicting wave directions has been chosen to be at a site where data is available to check the model.

Many forecasting models such as autoregressive integrated moving average (ARIMA) rely on the linear principles for part of the model. This causes problems with directional data as 0 and 360 degrees are equal, but this is not accounted for in a linear model. Therefore a model that wraps round is required for directional data. The Von Mises mixture distribution is used.

The Von Mises distribution is a statistical distribution used for directional data. It is sometimes referred to as an equivalent of the normal distribution for directional data. The Von Mises distribution is characterised by two parameters, the circular mean and the concentration parameter $\kappa$. The Von Mises probability density function is calculated by

$v M_{j}\left(\theta ; \mu_{j}, \kappa_{j}\right)=\frac{1}{2 \pi I_{0}\left(\kappa_{j}\right)} \exp \left[\kappa_{j} \cos \left(\theta-\mu_{j}\right)\right]$

Where $\mu_{\mathrm{j}}$ is the mean direction and $\mathrm{k}_{\mathrm{j}}$ is the concentration parameter (Carta et al. 2008). The modified Bessel function $\left(\mathrm{I}_{0}\left(\mathrm{k}_{\mathrm{j}}\right)\right)$ of the first kind and order zero is given by:

$$
I_{0}\left(k_{j}\right)=\frac{1}{\sqrt{2 \pi}} \int_{0}^{2 \pi} \exp \left[k_{j} \cos \theta\right] d \theta=\sum_{k=0}^{\infty} \frac{1}{(k !)^{2}}\left(\frac{k_{j}}{2}\right)^{2 k}
$$

This study proposes a conditional forecast of wave direction at Gabbard based on wave directions at Southwold. A Gaussian copula is used to capture the conditional dependence between the two sites. Dividing the historical wave direction data in half allows the first half to be used to train the model while the second is used as the conditional and to check the forecast accuracy.

A Copula can be used to form the joint distribution between two or more variables. A conditional copula can be formed to describe the conditional distribution of one variable given the other variable takes a particular value. (Frees and Valdez, 1998). Sklar's theorem states:

$$
P(G, S)=P(G) C(F(G), H(S)) P(S)
$$

Where in this case $\mathrm{P}(\mathrm{G}, \mathrm{S})$ is the joint probability distribution of wave directions at Gabbard $(G)$ and Southwold $(\mathrm{S})$. $\mathrm{P}(\mathrm{G})$ and $\mathrm{P}(\mathrm{S})$ are the individual respective probability distributions for Gabbard and Southwold. $F(G)$ and $H(S)$ are a function of the wave directions at the respective sites. Here the transform denoted by $\mathrm{F}$ and $\mathrm{H}$ is the Von Mises cumulative distribution function.
The wave directions observations at the historical site are used to correlate trends between the two sites. This is used with the current data at the other site to predict wave directions. This methodology utilises the Gaussian copula to relate uniform variables. A Von Mises transform is applied to give uniform variables. The model uses data from two sites to form a forecast at one site. The Von Mises probability density function is used to estimate the parameters for the cumulative distribution functions. The correlation is calculated based on the Von Mises transformed variables. The joint bivariate distribution of the historical data and a random forecasting variable is formed, this is the Gaussian Copula. The probability density function of a Von Mises distribution is then used with Bayes and Sklar theorems to get the joint conditional probabilities of wave directions at Gabbard given wave directions at Southwold. Bayes theorem states:

$$
P(G \mid S)=\frac{P(G, S)}{P(S)}
$$

Substituting Sklar theorem for $\mathrm{P}(\mathrm{G}, \mathrm{S})$ in Bayes theorem gives:

$$
P(G \mid S)=P(G) C(F(G), H(S))
$$

This means that the probability of a given wave direction at Gabbard given the wave direction at Southwold; $\mathrm{P}(\mathrm{G} \mid \mathrm{S})$; is equal to the probability of wave directions at Gabbard multiplied by the copula. The forecast for the probability is the maximum likelihood from the random value simulated over the range of the forecast. The maximum likelihood is the most likely wave direction; this value is used as the forecast at that timestep. Iterations of the formation of the joint distribution and forming a forecast from the maximum likelihood of the conditional probabilities are used to forecast at subsequent time steps.

\section{RESULTS}

A section of the data was taken between 01-Apr2010 and 23-Apr-2010 to provide a forecast. Figure 6 shows that the forecast wave direction tracks the actual wave direction to an extent although there are discrepancies as these change faster.

Mean absolute error (MAE) and mean absolute percentage error (MAPE) were calculated for the copula forecast and a persistence forecast for comparison. The copula forecast based on the methodology in section 5 performed better for both MAE and MAPE than the persistence forecast. The MAE and MAPE in Table 3, are calculated based on the directional difference between adjacent values, $\Delta$ signifies the presented values are the differences. 


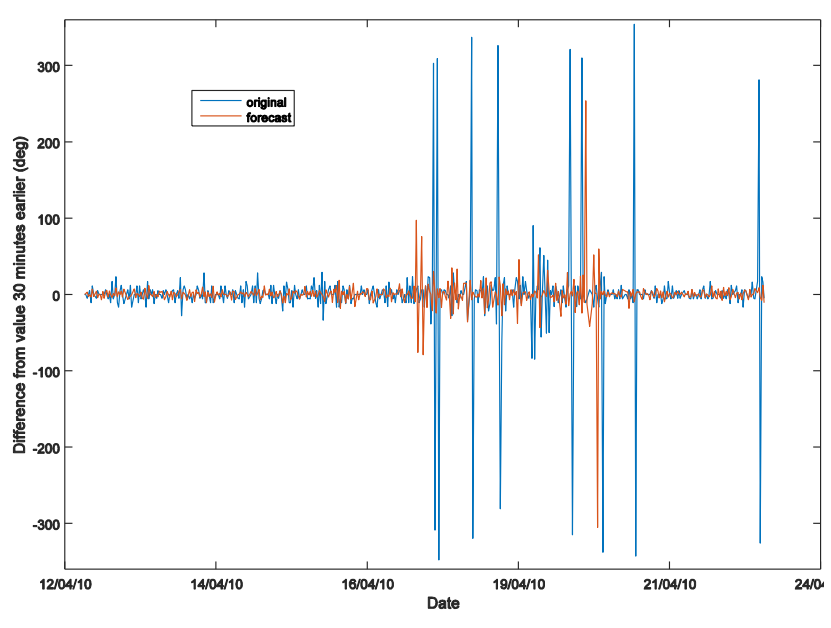

Figure 6. Tracking of wave direction for Gabbard.

Table 3. MAE \& MAPE for forecast tracking

\begin{tabular}{lll}
\hline & MAE & MAPE \\
\hline$\Delta$ Copula forecast & 22.9 & 159.2 \\
$\Delta$ Persistence forecast & 34.7 & 255.7
\end{tabular}

\section{CONCLUSIONS}

The paper analyses wind speed and wave height data and their respective directions. Use of directional means for bimodal data can produce unreliable results. Frequent low wind speeds can confuse the results. The results show that wave data for the two sites is bimodal while for the wind data there is a single mode. The two modes for wave direction could be caused by local currents or seabed conditions. A sand bar, for example, could result in negligible waves from a particular direction which might otherwise be the dominate direction for wind generated waves. Ideally, a longer period than three years would be common between the datasets.

A pilot study for 2012 showed similar trends for the wave data at the two sites to those for the longer periods of data, see Table 2 for the data coverage. For wind speeds for Yarmouth the general trends for the one year of 2012 and the larger periods of observation between 2002 and 2012 showed similar key directional patterns. However, the longer period did show more significant difference than was observed for the wave data. In this study frequency of wave heights above $2.1 \mathrm{~m}$ and wind speed above $10 \mathrm{~m} / \mathrm{s}$ are negligible for all directions meaning that it is difficult to draw conclusions with regards to key directions in these conditions. However conditions in high but not extreme conditions are most important for this study as for hours when waves are above $1.5 \mathrm{~m}$ then personnel transfers using crew transfer vessel would not be possible. Additionally, jack-up vessels will be impacted by wave directions during jacking-up operations but will be less affected by this after completion of the jacking-up process.
Leg-stabilised vessels have a maximum wave height of $0.5 \mathrm{~m}$ so will be heavily dependent on the conditions at these lower wave heights.

The results have shown clear regimes exist at the specific sites for waves at these lower wave heights. Therefore, the developed forecasts of the direction of waves may help to inform whether wave heights will be statistically more likely to be above thresholds at sites where historical data is available or historical data is available at nearby sites representative of those locations. This could be done by assessing whether the forecasted direction of waves is in a direction where high waves for that site are statistically more likely. The layout of the wind farm and the required orientation of maintenance vessels could also be important. If wave heights are close to the threshold of $1.5 \mathrm{~m}$ for crew transfers from crew transfer vessels, then the actual direction of waves may be a deciding factor. Waves in a direction that pushes a crew transfer vessels away from the turbine during transfer operation may make transfers unsafe when transfers with a similar wave height from a different direction could be suitable.

Future work could investigate alternative sources of data. One possible additional source of data would be to use wind speed and direction data recorded at Egmond aan Zee Wind Farm, OWEZ (NoordzeeWind 2010). This site also records wave data, however, limited data is available. There are additional CEFAS sites providing wave data within the area (Centre for Environment Fisheries and Aquaculture Science 2016).

The directional forecasting methodology could also be applied to wind or marine current direction data. The copula model could also include wind speed or wave heights in the model. While this study presents a copula with two inputs, there is the potential in future work for the inclusion of multiple input parameter or geographical sites.

\section{ACKNOWLEDGEMENTS}

This work has been funded by the EPSRC, project reference number EP/G037728/1.

\section{REFERENCES}

4C Offshore. 2015. Project Details for East Anglia One. Online: www.4coffshore.com/windfarms/east-anglia-oneunited-kingdom-uk64.html [Accessed 08/09/15].

Andreas, E. L. \& Wang, S. 2007. Predicting significant wave height off the northeast coast of the United States. Ocean Engineering, 34(8-9): 1328-1335.

Browell, J. Dinwoodie, I. \& McMillan, D. 2016. Forecasting for Offshore Maintenance Scheduling under Uncertainty. European Safety and Reliability. Glasgow, UK.

BVG Associates. 2010. A Guide to an Offshore Wind Farm. Online: www.thecrownestate.co.uk/media/5408/ei-km-in-sc- 
supply-012010-a-guide-to-an-offshore-wind-farm.pdf [Accessed 01/07/15] Crown Estate.

Carta, J. A. Bueno, C. \& Ramírez, P. 2008. Statistical modelling of directional wind speeds using mixtures of von Mises distributions: Case study. Energy Conversion and Management, 49(5), pp 897-907.

Centre for Environment Fisheries and Aquaculture Science (CEFAS). 2016. WaveNet. Online: www.cefas.co.uk/cefasdata-hub/wavenet [Accessed 09/01/15] Crown Copyright.

Civil Aviation Authority of New Zealand. 2012. Helicopter Performance. Civil Aviation Authority of New Zealand: Wellington. Online: www.caa.govt.nz [29/07/16]

Crown Estate. 2016. Offshore wind operational report. The Crown Estate. p. 1-18. Online: www.thecrownestate.co.uk/ media/5462/ei-offshore-wind-operational-report-2016.pdf [Accessed 29/07/16]

Dalgic, Y. Lazakis, I. \& Turan, O. 2013. Vessel charter rate estimation for offshore wind O\&M activities. Developments in Maritime Transportation and Exploitation of Sea Resources. CRC Press.

Dalgic, Y. Lazakis, I. Dinwoodie, I. McMillan, D. \& Revie, M. 2015a. Advanced logistics planning for offshore wind farm operation and maintenance activities. Ocean Engineering, 101: 211-226.

Dalgic, Y. Lazakis, I. \& Turan, O. 2015b. Investigation of Optimum Crew Transfer Vessel Fleet for Offshore Wind Farm Maintenance Operations. Wind Engineering, 39(1): 31-52.

Dinwoodie, I. A. McMillan, D. \& Quail, F. 2012. Analysis of offshore wind turbine operation \& maintenance using a novel time domain meteo-ocean modeling approach. ASME Turbo Expo 2012, Copenhagen, Denmark, 11-15 June 2012: 1-11.

Dinwoodie, I. A. McMillan, D. Revie, M. Lazakis, I. \& Dalgic, Y. 2013. Development of a combined operational and strategic decision support model for offshore wind. Energy Procedia, 35: 157-166.

Dinwoodie, I. A. Endrerud, O.-E. Hofmann, M. Martin, R. \& Bakken Sperstad, I. 2015. Reference cases for verification of operation and maintenance simulation models for offshore wind farms. Wind Engineering, 39(1): 1-14.

Dominguez-Navarro, J. A. Dinwoodie, I. \& McMillan, D. 2014. Statistical forecasting for offshore wind helicopter operations. Probabilistic Methods Applied to Power Systems (PMAPS), 2014 International Conference on, Durham, 7-10 July 2014: 1-6.

Dowell, J. Walls, L. Zitrou, A. \& Infield, D. Analysis of wind and wave data to assess maintenance access for offshore wind farms. European Safety and Reliability Conference (ESREL), Sept 2013 Amsterdam, Netherlands.

Espejo, A. Minguez, R. Tomas, A. Menendez, M. Mendez, F.J. \& Losada, I.J. 2011. Directional calibrated wind and wave reanalysis databases using instrumental data for optimal design of off-shore wind farms. OCEANS, 6-9 June 2011. Santander, Spain. IEEE, 1-9.

Feuchtwang, J. \& Infield, D. 2013. Offshore wind turbine maintenance access a closed-form probabilistic method for calculating delays caused by sea-state. Wind Energy, 16(7): 1049-1066.

Frees, E. W. \& Valdez, E. A. 1998. Understanding Relationships Using Copulas. North American Actuarial Journal, 2(1), pp 1-25.

HGO InfraSea Solutions. 2014. Heavy-lift jack-up vessel, INNOVATION - Power of Performance. Bremen, Germany: HGO InfraSea Solutions GmbH \& Co. KG.

Hill, D. Bell, K. McMillan, D. \& Infield, D. 2014. A vector auto-regressive model for onshore and offshore wind synthesis incorporating meteorological model information. Advances in Science and Research, 11: 35-39.
Hofmann, M. 2011. A Review of Decision Support Models for Offshore Wind Farms with an Emphasis on Operation and Maintenance Strategies. Wind Engineering, 35(1): 1-15.

NoordzeeWind 2010. Reports \& Data. Online: http://www.noordzeewind.nl/en/knowledge/reportsdata/ [Accessed 09/08/15].

Peña, A. \& Gryning, S.-E. 2008. Charnock's Roughness Length Model and Non-dimensional Wind Profiles Over the Sea. Boundary-Layer Meteorology, 128(2): 191-203.

Rademakers, L. Braam, H. Obdam, T. \& Pieterman, R. 2014. Operation and Maintenance Cost Estimator (OMCE), Energy Research Centre of the Netherlands (ECN) Online.

Shafiee, M. 2015. Maintenance logistics organization for offshore wind energy: Current progress and future perspectives. Renewable Energy, 77: 182-193.

Stephen, B. Galloway, S. McMillan, D. Anderson, L. \& Ault, G. 2013. Statistical profiling of site wind resource speed and directional characteristics. IET Renewable Power Generation, 7(6): 583-592.

Szelangiewicz, T. \& Żelazny, K. 2006. Calculation of the mean long-term service speed of transport ship. Part. I. Resistance of ship sailing on regular shipping route in real weather conditions. Polish Maritime Research, 23-31.

UK Meteorological Office. 2015. Met Office Integrated Data Archive System (MIDAS) Land and Marine Surface Stations Data (1853-current), [Online].NCAS British Atmospheric Data Centre, 2012. 